\title{
The improvement of gamma irradiation resistance of superhydrophobic coating with MWCNTs
}

\author{
Jing Zhang ${ }^{1}$, Yan Zhang ${ }^{1, *}$ and Yujian Liu ${ }^{1, *}$ \\ Key Laboratory of Specially Functional Polymeric Materials and Related Technology of Ministry of Education, School of Materials \\ Science and Engineering, East China University of Science and Technology, Shanghai 200237, China
}

\begin{abstract}
A superhydrophobic coating with excellent water repellence and gamma irradiation resistance was obtained by multi-walled carbon nanotubes (MWCNTs) modification. The effects of MWCNTs on the mechanical behaviour, water contact angle (WCA) and self-cleaning properties of the coatings were investigated. After $1.23 \times 10^{7} \mathrm{rad}$ dose of gamma irradiation, WCA of the coating without MWCNTs modification (EPPM0) decreases from $150^{\circ}$ to $140^{\circ}$ and the adhesion reduces from $5 \mathrm{~B}$ to $4 \mathrm{~B}$, respectively. While the coating (EPPM3) with $3 \mathrm{wt} \%$ MWCNTs modification remains high WCA $\left(152^{\circ}\right)$, excellent adhesion $(5 \mathrm{~B})$ and hardness $(6 \mathrm{H})$. The results of dust removal test suggest that the coating still maintains self-cleaning property after high dose gamma irradiation.
\end{abstract}

\section{Introduction}

With the rapid progress of nuclear energy, nuclear safety has become a hot issue in the worldwide [1, 2]. In nuclear accidents, large amounts of radioactive elements and high-energy gamma rays would be released [3-5]. The settled dusts can cause secondary pollution with the movement of mobile devices. Superhydrophobic coating allows water droplets to roll simultaneously towards all directions, removing the contaminants for its high water repellence [6].

Owning to its wide applications, many efforts are tried to fabricate superhydrophobic coating. For example, Ailan $\mathrm{Qu}$ [7] prepared a fluorine-silicon copolymer $/ \mathrm{SiO}_{2}$ superhydrophobic coating. Xiaotao Zhu [8] obtained a superhydrophobic coating by using $\mathrm{Ag}$ particle deposition and polyethylene as the matrix. These superhydrophobic coatings are usually based on low surface energy substances such as fluorine-containing compounds and silicone resins. Compared with irradiation sensitive fluorine-containing compounds and silicone resins, epoxy resin is widely used in nuclear environment for its good adhesion, chemical resistance and mechanical properties [9]. However, under very high energy and strong penetration of gamma rays, some weak chemical bonds of the resins would be broken, resulting in the performance of the coating decreasing or even losing its function [10]. Multi-walled carbon nanotubes (MWCNTs) exhibit excellent abrasion resistance, hydrophobicity, especially radiation resistance. It can be filled in matrix to improve the properties of the composite coating [11-13]. For instance, the effect of MWCNTs on the performance of ultrahigh molecular weight polyethylene (UHMWPE) composites after gamma irradiation was studied by M.J. MartínezMorlanes [14]. The results showed that with the introduction of MWCNTs, the radiation-induced radicals are decrease and the crosslinking density of UHMWPE remains unchanged.

In this paper, superhydrophobic coating was obtained by using epoxy resin copolymerized with the hydroxylterminated polymethylphenylsiloxane (EP/HT-PMPS) as the matrix and $\mathrm{SiO}_{2}$ nanoparticles as the fillers. Moreover, MWCNTs was selected to improve the gamma irradiation resistance. The effect of MWCNTs amount on the mechanical behaviour, water contact angle as well as self-cleaning properties of the coating under high dose gamma rays was investigated.

\section{Experimental section}

\subsection{Materials}

Epoxy resin (EP) was obtained from Shanghai Huayi Resin Co., Ltd. Hydroxyl-terminated polymethylphenylsiloxane (HT-PMPS) was purchased from Dow Corning (Shanghai) Co., Ltd. Isophorone diamine and multi-walled carbon nanotubes (MWCNTs) were got from Shanghai Aladdin Biochemical Reagent Co., Ltd. The $\mathrm{SiO}_{2}$ nanoparticles were self-prepared.

\subsection{Fabrication of superhydrophobic coating}

Superhydrophobic coating was prepared according to our pervious method [15], and the MWCNTs were introduced to improve the gamma resistance of the coating. Epoxy resin (EP) modified by hydroxyl-

*Corresponding author: yzhang@ecust.edu.cn; Yu-Jian: yjliu@ecust.edu.cn 
terminated polymethylphenylsiloxane (HT-PMPS) were put into a flask with $\mathrm{SiO}_{2}$ particles together, then different amounts of MWCNTs (0 wt $\%, 1 \mathrm{wt} \%, 1.5 \mathrm{wt} \%$, $2 \mathrm{wt} \%, 2.5 \mathrm{wt} \%, 3 \mathrm{wt} \%, 3.5 \mathrm{wt} \%$ ) were added. By using isophoronediamine as the curing agent, the mixture was coated on tinplate to obtain a composite coating after well agitation. The as-prepared coating was designated as EPPM0, EPPM1, EPPM1.5, EPPM2, EPPM2.5, EPPM3, and EPPM3.5, respectively.

\subsection{Characterization}

The adhesion and hardness of the coating were assessed according to EN ISO 2409-2013 and EN ISO 151842012 standards, respectively. The water contact angles (WCA) were measured using contact angle tester (JC2000D2, Powereach, China). The samples were irradiated by Co-60 gamma irradiation (Institute of Nuclear Technology Application, ECUST) with total doses of $8.33 \times 10^{5} \mathrm{rad}, 1.54 \times 10^{6} \mathrm{rad}, 2.26 \times 10^{6} \mathrm{rad}$, $5.11 \times 10^{6} \mathrm{rad}$ and $1.23 \times 10^{7} \mathrm{rad}$, respectively. Dirtremoval test was carried out by using graphite as the artificial powders. The slant angle of surface is $6^{\circ}$.

\section{Results and discussions}

\subsection{Adhesion and Hardness of the composite coating}

The adhesion and hardness of the composite coatings with different amounts of MWCNTs are showed in Figure 1 and Figure 2.

The hardness of all composite coatings (EPP0 EPPM3.5) is as high as $6 \mathrm{H}$, indicating that the amount of MWCNTs has no influence on the hardness of the composite coating. It should be attributed to the excellent hardness of MWCNTs. While with the increase of the amount of MWCNTs, the adhesion of composite coating stays the same at first. When the amount of MWCNTs is $3.5 \mathrm{wt} \%$, the adhesion of composite coating drops to 4B. Epoxy resin matrix contains many polar bonds like hydroxyl groups and ether bonds, which have good adhesion with metal substrates. However, the interaction strength between the MWCNTs and metal substrates is poor. Therefore, with the increase of MWCNTs amount, the adhesion of composite coating would decrease.

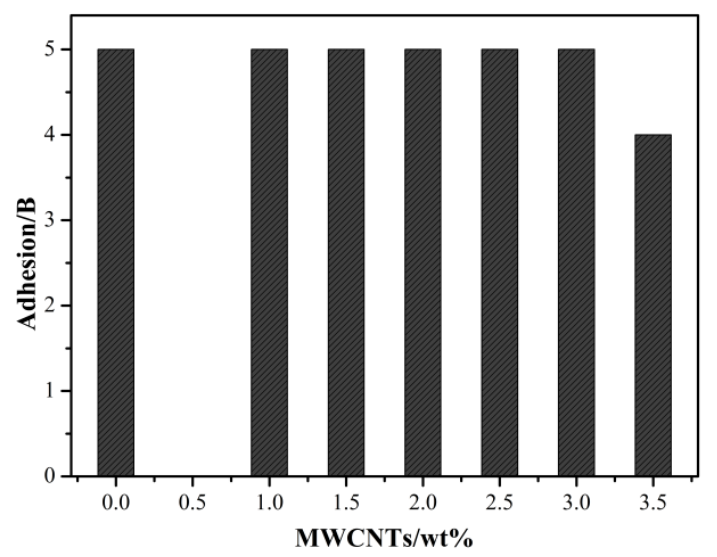

Figure 1. Adhesion of the composite coatings with different mass of MWCNTs

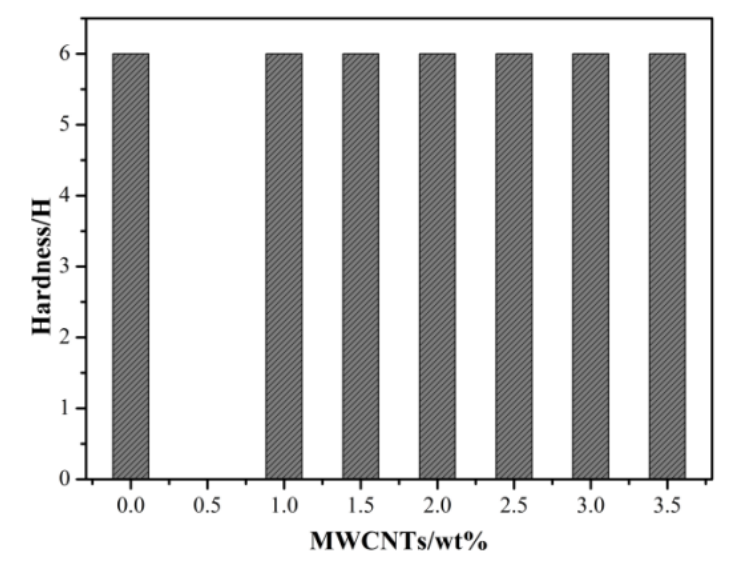

Figure 2. Hardness of the composite coatings with different mass of MWCNTs

\subsection{Gamma irradiation resistance}

The adhesion and hardness of the composite coatings with different mass of MWCNTs after gamma irradiation were followed. The irradiation dose was $8.33 \times 10^{5} \mathrm{rad}$, $1.54 \times 10^{6} \mathrm{rad}, 2.26 \times 10^{6} \mathrm{rad}, 5.11 \times 10^{6} \mathrm{rad}$, and $1.23 \times 10^{7}$ rad, respectively. The results are listed in Table 1 and 2 .

Table 1. Adhesion of the composite coatings with different mass of MWCNTs after gamma irradiation

\begin{tabular}{ccccccc}
\hline $\begin{array}{l}\text { Radiation } \\
\text { doses/rad }\end{array}$ & EPPM0 & EPPM1 & EPPM1.5 & EPPM2 & EPPM2.5 & EPPM3 \\
\hline $8.33 \times 10^{5}$ & $5 \mathrm{~B}$ & $5 \mathrm{~B}$ & $5 \mathrm{~B}$ & $5 \mathrm{~B}$ & $5 \mathrm{~B}$ & $5 \mathrm{~B}$ \\
$1.54 \times 10^{6}$ & $5 \mathrm{~B}$ & $5 \mathrm{~B}$ & $5 \mathrm{~B}$ & $5 \mathrm{~B}$ & $5 \mathrm{~B}$ & $5 \mathrm{~B}$ \\
$2.26 \times 10^{6}$ & $5 \mathrm{~B}$ & $5 \mathrm{~B}$ & $5 \mathrm{~B}$ & $5 \mathrm{~B}$ & $5 \mathrm{~B}$ & $5 \mathrm{~B}$ \\
$5.11 \times 10^{6}$ & $5 \mathrm{~B}$ & $5 \mathrm{~B}$ & $5 \mathrm{~B}$ & $5 \mathrm{~B}$ & $5 \mathrm{~B}$ & $5 \mathrm{~B}$ \\
$1.23 \times 10^{7}$ & $4 \mathrm{~B}$ & $4 \mathrm{~B}$ & $5 \mathrm{~B}$ & $5 \mathrm{~B}$ & $5 \mathrm{~B}$ & $5 \mathrm{~B}$ \\
\hline
\end{tabular}


Table 2. Hardness of the composite coatings with different mass of MWCNTs after gamma irradiation

\begin{tabular}{ccccccc}
\hline Radiation doses $/ \mathrm{rad}$ & EPPM0 & EPPM1 & EPPM1.5 & EPPM2 & EPPM2.5 & EPPM3 \\
\hline $8.33 \times 10^{5}$ & $6 \mathrm{H}$ & $6 \mathrm{H}$ & $6 \mathrm{H}$ & $6 \mathrm{H}$ & $6 \mathrm{H}$ & $6 \mathrm{H}$ \\
$1.54 \times 10^{6}$ & $6 \mathrm{H}$ & $6 \mathrm{H}$ & $6 \mathrm{H}$ & $6 \mathrm{H}$ & $6 \mathrm{H}$ & $6 \mathrm{H}$ \\
$2.26 \times 10^{6}$ & $6 \mathrm{H}$ & $6 \mathrm{H}$ & $6 \mathrm{H}$ & $6 \mathrm{H}$ & $6 \mathrm{H}$ & $6 \mathrm{H}$ \\
$5.11 \times 10^{6}$ & $6 \mathrm{H}$ & $6 \mathrm{H}$ & $6 \mathrm{H}$ & $6 \mathrm{H}$ & $6 \mathrm{H}$ & $6 \mathrm{H}$ \\
$1.23 \times 10^{7}$ & $5 \mathrm{H}$ & $5 \mathrm{H}$ & $6 \mathrm{H}$ & $6 \mathrm{H}$ & $6 \mathrm{H}$ & $6 \mathrm{H}$ \\
\hline
\end{tabular}

It can be seen that the adhesion and hardness of the composite coatings remain stable when the irradiation dose varied in the range of $8.33 \times 10^{5} \sim 5.11 \times 10^{6} \mathrm{rad}$. The good gamma irradiation stability results from the high crosslinking density and abound benzene rings of the epoxy resins. Nevertheless, further increasing radiation doses to $1.23 \times 10^{7} \mathrm{rad}$, the adhesion of the coating without MWCNTs modification (EPPM0) decreases from $5 \mathrm{~B}$ to $4 \mathrm{~B}$, and its hardness also reduces from $6 \mathrm{H}$ to $5 \mathrm{H}$. When the amount of MWCNTs is greater than 1.5 wt $\%$, the composite coatings maintain excellent adhesion $(5 \mathrm{~B})$ and hardness $(6 \mathrm{H})$ even under the high gamma irradiation of $1.23 \times 10^{7}$ rad dose.

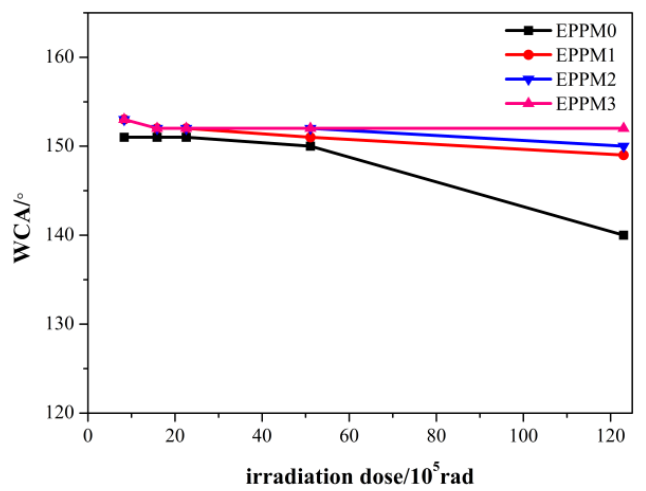

Figure 3. WCA of the composite coatings with different mass of MWCNTs after different dose of gamma irradiation

In order to further investigate the change of superhydrophobicity, WCA of the composite coatings with different amount of MWCNTs after gamma irradiation is displayed in Figure 3. Superhydrophobic surfaces are characterized as those with the water contact angles exceeding $150^{\circ}$ [16]. It is like that of hardness and adhesion, WCA of the coating without MWCNTs (EPPM0) modification decreases from $150^{\circ}$ to $140^{\circ}$ after irradiated by $1.23 \times 10^{7}$ rad dose of gamma rays, implying losing the superhydrophobic performance. The epoxy resin owns good gamma radiation stability. Whereas when the irradiation doses are very high, some weak bond like $\mathrm{C}-\mathrm{N}$ and $\mathrm{C}-\mathrm{C}$ begin to rupture and produce free radicals, leading to further crosslinking and degradation, as illustrated in Scheme 1 [17]. Therefore, the performance of the composite coating declined under high gamma radiation.

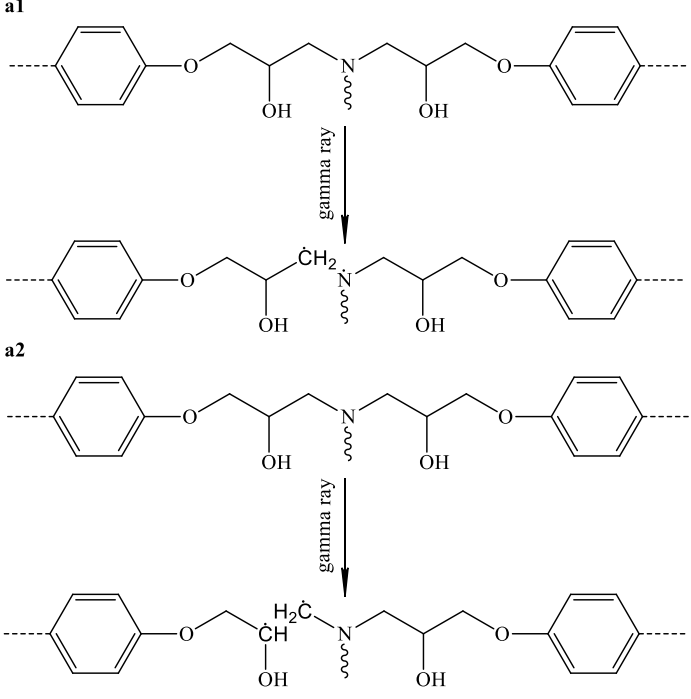

Scheme 1. Chemical bonds rupture of epoxy resin after irradiation. Rupture of C-N (a1) and C-C (a2)

While with the content of MWCNTs increasing, the gamma irradiation resistance of the composite coatings is improved. Especially for the coating with $3.0 \mathrm{wt} \%$ MWCNTs (EPPM3), its WCA still remains of $152^{\circ}$ after $1.23 \times 10^{7}$ rad dose of gamma irradiation, indicating good superhydrophobic performance. The MWCNTs itself has high radiation stability. At the same time, the sp2 hybrid orbital of the MWCNTs can absorb free radicals induced by gamma irradiation, thus slowing down the degradation rate of the coating effectively $[11,14]$. The illustration of the absorbing mechanism is showed in Scheme 2.

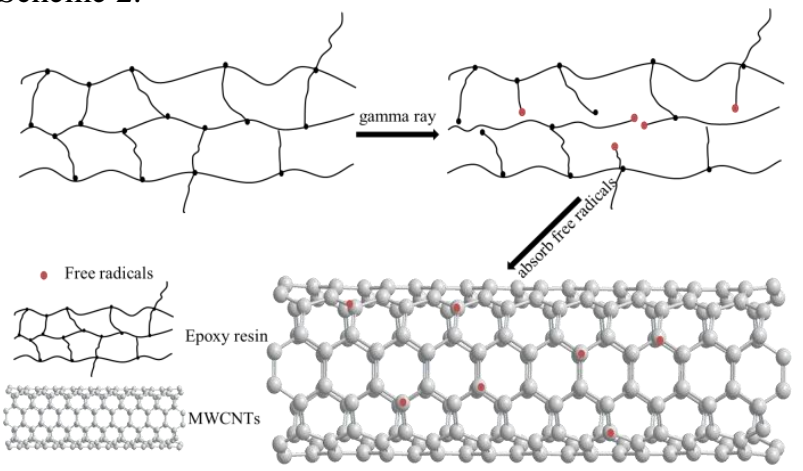

Scheme 2. Illustration of the absorbing mechanism for the MWCNTs in the epoxy resin matrix

\subsection{Self-cleaning}

The removal process of radioactive dust was simulated by using graphite powder as the artificial dust. After 
$1.23 \times 10^{7} \mathrm{rad}$ dose of gamma irradiation, the water droplets roll from the top to the bottom along the coating's (EPPM3) surface. It forms spherical shapes and rolls on the surface freely, leaving a clean surface as shown in Fig 4A D. The results of easy removal of dust indicate that the surfaces maintain their water repellence and dirt-removal properties even exposed to $1.23 \times 10^{7} \mathrm{rad}$ dose of gamma irradiation.

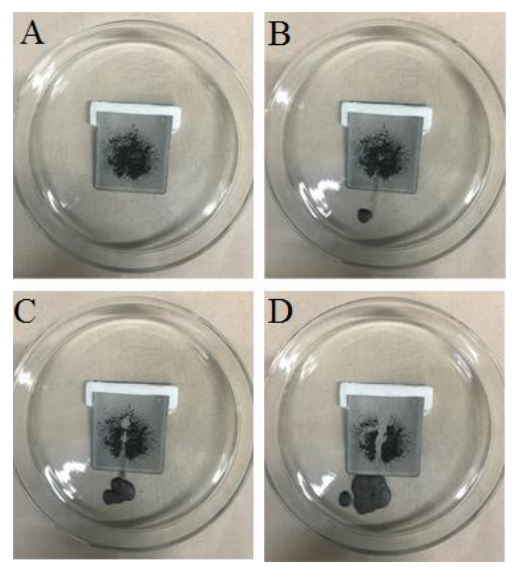

Figure 4. Process of self-cleaning of the coating (EPPM3) after irradiation

\section{Conclusions}

The superhydrophobic coating was obtained by using EP/HT-PMPS resins as the matrix and silica particles as the fillers. Furthermore, multi-walled carbon nanotubes (MWCNTs) were selected to further improve gamma radiation resistance of the composite coatings. When the amount of MWCNTs reaches $3.0 \mathrm{wt} \%$, the composite coating (EPPM3) retains a superior performance with a high WCA $\left(152^{\circ}\right)$, excellent adhesion (5B) and strong hardness $(6 \mathrm{H})$ even after $1.23 \times 10^{7}$ rad dose of gamma irradiation. In addition, the results of dust removal test demonstrated that the surface still maintains its water repellence when exposed to high irradiation.

\section{Acknowledgements}

This work was supported by the National Basic Research Program of China (973 program) (NO.2013CB035505), the Fundamental Research Funds for the Central Universities (222201717001).

\section{References}

1. W Zeng. Beijing Review. Beijing Review 14, 36-37, (2013).

2. L, Andrew. The Engineer 293, 668 (2005).

3. P D Holt, J A B Gibson. J Nucl Energ 19, 1 (1965).

4. J T Smith, R N J Comans, N A Beresford, et al. Nature 405, 6783 (2000).

5. Y Chang, Y Zhao. Mar. Pollut. Bull 64, 5 (2012).

6. S Ding, T Xiang, C Li, et al. Mater. Des 117, (2017).
7. A Qu, X Wen, Pi P, et al. J. Colloid Interface Sci 317, 1 (2008).

8. X Zhu, Z Zhang, X Men, et al. J. Mater. Chem 21, 39 (2011).

9. D Pintoa, L Bernardob, A Amaroa, et al. Constr. Build. Mate 95, (2015).

10. L Chang, Y Zhang, Y Liu, et al. Nucl Instrumment B 356-357, (2015).

11. A Galano. J Phys Chem C 112, 24 (2008).

12. S H Lu, M H N Tun, Z J Mei, et al. Langmuir 25, 21 (2009).

13. B Zhang, S Xie, R Wei, et al. Sci China Chem 59, 3 (2016)

14. M J Martínez-Morlanes, P Castell, P J Alonso, et al. Carbon 50, 7 (2012).

15. Y Zhang, F Ren, Y Liu. Appl. Surf. Sci 436, (2018).

16. E Celia, T Darmanin, E T Givenchy, et al. J. Colloid Interface Sci 402, (2013).

17. F Diao, Y Zhang, Y Liu, et al. Nucl Instrumment B 383, (2016). 